\title{
Difficult airways in ENT surgery
}

\author{
Radichkova V.', B. Mladenov² \\ 'Department of Anesthesiology and Intensive Care; University Hospital "Queen Giovanna"- ISUL; \\ Medical University-Sofia \\ ${ }^{2}$ Dpt. Pediatric Anesthesiology and Intensive Care University Emergency Hospital "N.I.Pirogov" Sofia, Bulgaria
}

\begin{abstract}
Theoretical basis: Airway management for laryngeal surgery require the anesthesiologist to be adept with various methods of managing the difficult airway and performing airway exchange, to competently execute intraoperative ventilation strategies, to be proficient with inhalational and total intravenous anesthesia, and to quickly tailor anesthetic techniques to the various durations of the surgical cases.Results: When the surgical site is within or near the airway, coordination between the anesthesia and surgical teams is essential to consider the need for an ETT, which tube type to use, the oxygen enrichment plan, and mode of ventilation. The presence of laryngeal carcinoma requires precise assessment of the feasibility of endotracheal intubation. Tracheostomy can be safely performed under general anesthesia with laryngeal mask ventilation. The essential requirements for precision microlaryngeal surgery and optimal preservation of function include a clear and still surgical field, absence of patient movement, and allocation of sufficient time to carefully complete the procedure in an unhurried manner. Postoperative hemorrhage is the most serious complication of tonsillectomy. Aspiration of foreign bodies by children is a common problem around the world. Conclusion: General anesthesia in ENT surgery represents a unique example of close cooperation between the surgeon and the anesthesiologist.
\end{abstract}

Key words: Difficult airways, tracheostomy, general anesthesia, airway management.

\section{Literature review}

Advancesanddemandsofthenewsurgical techniques and an expanding patient population that was previously considered unsuitable for surgery have created novel challenges for the anesthesiologist. State-of-the-art anesthesia and airway management for laryngeal surgery require the anesthesiologist to be adept with various methods of managing the difficult airway and performing airway exchange, to competently execute intraoperative ventilation strategies, to be proficient with inhalational and total intravenous anesthesia, and to quickly tailor anesthetic techniques to the various durations of the surgical case.

\section{Laser surgery of the larynx}

Laser is an acronym for light amplification by stimulated emission of radiation-a highly collimated beam of photons at a single frequency. Lasers are ubiquitous in the modern world and are increasingly used in the operating room (OR). ${ }^{1}$ When the surgical site is within or near the airway, coordination between the anesthesia and surgical teams is essential to consider the need for an ETT, which tube type to use, the oxygen enrichment plan, and mode of ventilation. If intubation is planned, then varied intubation options exist and include an assortment of available ETTs and 
jet ventilation catheters. A few oxygenationventilation strategies include ventilating through a cuffed or tightly fitting ETT, either continuously or intermittently using a ventilator with apnea during episodic removal of the ETT to allow unobstructed access to the surgical field. Either supraglottic or infraglottic catheter positioning may be selected for jet ventilation. In addition, the choice of anesthetic must be considered. There are series using sevoflurane and spontaneous ventilation ${ }^{2}$; however, volatile anesthetics are not reliably delivered to the patient if jet ventilation is required, and the vapors can pollute the OR. Finally, although the volatile anesthetics currently used in clinical practice are nonflammable and nonexplosive in clinically relevant concentrations ${ }^{3}$ when exposed to flame, they may pyrolyse to potentially toxic compounds. ${ }^{4}$ ETT fires have their own set of elevated risks for the patient and require swift corrective measures. With the right conditions and if properly managed an ignited ETT may cause little if any harm. However, catastrophic injury may occur. ${ }^{5,6}$ If ignited and combustion breaches the ETT with its centrally flowing reservoir of oxidizer, a blowtorch scenario in the airway can occur. The potential for far-reaching thermal injury to the pulmonary tract exists. In addition, products of complete and partial combustion including smoldering debris, particulate matter, toxic gases, and compounds may cause further insult. When using a laser near the airway, the updated 2013 ASA Practice Advisory strongly agrees that "laser resistant tracheal tubes [and catheters] should be used, and that the tube choice should be appropriate for the procedure and the laser..." If a cuffed tube is used, then the cuff should be filled with saline rather than air whenever feasible. ${ }^{7}$ Methylene blue-dyed saline may help speed identification of cuff breaches. ${ }^{8}$ Added protection from ignition may be achieved by using water-soaked sponges around the tube at the site of work and at the glottis. These sponges may seal leaks of oxygen around an ill-fitting ETT cuff, segregating the higher $\mathrm{FiO}_{2}$ being delivered to the patient from the ambient air above the glottis and may protect the tube from laser strikes by adding a layer of water-saturated protection. ${ }^{9}$

\section{Total laryngectomy}

Laryngeal carcinoma is the eleventh of the most common malignant neoplasms found in men. Epidemiologically it represents $1.6-2 \%$ of all malignant tumors in males and $0.2-0.4 \%$ in females ${ }^{10}$. Surgical treatment of laryngeal carcinoma, partial or total laryngectomy, is an important part of the complex management of the disease. Total laryngectomy is a surgical procedure during which the larynx is totally removed and the airway is interrupted, respiration being performed through a tracheal stoma resulting from bringing the trachea to the skin in the lower anterior cervical area. ${ }^{11-}$ ${ }^{14}$ The presence of laryngeal carcinoma requires precise assessment of the feasibility of endotracheal intubation. Expectation of a difficult intubation requires a preliminary preparation for ventilation if endotracheal intubation is not possible. It is important to assess whether endotracheal intubation after induction in general anesthesia is possible or the tracheostomy should be performed in an awake patient with preserved spontaneous breathing under local anesthesia receiving supplementary oxygen via nasal oxygen catheter. ${ }^{15-22}$ The degree of laryngeal obstruction can be preoperatively evaluated by a detailed description of preliminary performed video laryngoscopy along with computer tomography examination results. The degree of laryngeal obstruction can be categorized using the CottonMyer scale for every patient. This evaluation will allow the clinician to choose the proper method for upper airway instrumentation. Induction into general anesthesia and endotracheal intubation as a method for upper airway instrumentation in patients with laryngeal carcinoma is dangerous and under debate because of: expected difficult intubation due to laryngeal obstruction by the tumor, tissue trauma (can cause bleeding and/or edema), transplantation of tumor cells into lower parts of the airways causing stoma recurrence. ${ }^{23-31}$ Tracheostomy can be safely performed under general anesthesia with laryngeal mask ventilation. This method for upper airway instrumentation has been recently introduced for patients with laryngeal carcinoma undergoing laryngectomies in the Department of Otorhinolaryngology at the University Hospital "Queen Giovanna" - ISUL, Sofia, Bulgaria. In a study conducted by Marinov et al. over 60 patients undergoing total laryngectomy, 20 of the patients underwent tracheostomy under general anesthesia and laryngeal mask ventilation. None of them suffered any significant complications, including desaturations, despite of the considerably high degrees of laryngeal obstruction caused by the tumor masses. ${ }^{32}$ 


\section{Microlaryngeal surgery}

The essential requirements for precision microlaryngeal surgery and optimal preservation of function include a clear and still surgical field, absence of patient movement, and allocation of sufficient time to carefully complete the procedure in an unhurried manner. The patient's airway must be protected from blood, debris, and irrigation fluid and ventilation must be adequately controlled. ${ }^{33}$ The anesthesiologist must safely share the patient's airway with the surgeon, and must be prepared to skillfully and confidently switch from one ventilation technique to another during the case if needed or dictated by surgery. In most surgical procedures, the patient's airway is shared with the surgeon, and immediate access to the airway is difficult or impossible because the operating room (OR) table is turned 90 or 180 degrees away from the anesthesiologist. The ETT must be secured diligently to prevent accidental extubation under the surgical drapes or withdrawal of the ETT into the larynx, resulting in a sudden air leak or possible compression of the anterior branch of the recurrent laryngeal nerve by the ETT cuff. ${ }^{34,35}$ Although advanced airway management techniques can be highly successful when direct laryngoscopy fails, the patient's unfavorable anatomy may not be modifiable for the surgical exposure, which requires the use of the largest operating laryngoscope and placement of the patient's head in the Boyce-Jackson position using a combination of cervical flexion and atlantooccipital extension. ${ }^{36,37}$ If suspension laryngoscopy fails or if the location of the lesion is not easily accessible, it can be performed, to the extent microlaryngeal surgery permits, with the help of the flexible fiberoptic bronchoscope (FFB) inserted through the laryngeal mask airway (LMA). ${ }^{38,39,40}$ The intubating laryngeal mask airway (iLMA) offers certain advantages, such as a rigid, wide metal tube that can accommodate a largediameter FFB, optimal alignment of the iLMA aperture with the glottic opening, diminished hemodynamic responses compared with suspension laryngoscopy, and superior ventilation capabilities. ${ }^{41-44}$ The iLMA is associated with an outstanding success rate for blind endotracheal intubation in patients with difficult airways. Unfortunately, the manufacturer-supplied iLMA ETTs are too big for most microlaryngeal surgery. An ETT with a smaller inner diameter (ID) (e.g., $5.0-\mathrm{mm}$ ID microlaryngeal tracheal [MLT] tube) is typically required to maximize the surgical view. Placement of MLT tubes through the iLMA can be achieved with the help of a small-diameter FFB; however, passage of the ETT through the laryngeal inlet into the trachea is blind. Blind advancement of the ETT may cause inadvertent laryngeal trauma and core out pedunculated supraglottic or glottic tumors, nodules, or cysts. ${ }^{45}$ When the FFB route (with or without the use of a supralaryngeal airway device) is chosen for endotracheal intubation, it is advantageous to closely match the outer diameter (OD) of the scope with the ID of the ETT to minimize the risk of complications associated with blind ETT advancement. Use of optical stylets (e.g., Bonfils, Shikani, Clarus Video System) may also be beneficial in that regard, because the ETT will follow the trajectory of the stylet navigated under direct vision through the vocal cords. However, most of the available adult-size stylets require the use of an ETT with a minimum ID of 5.5 to $6.0 \mathrm{~mm}$.

\section{Tonsillectomy}

For a patient with a bleeding oropharynx the anesthesiologist should follow the difficult airway guidelines developed by the American Society of Anesthesiologists (ASA). However, these guidelines or other available new or old modalities do not specifically address the management of a bleeding airway. ${ }^{46}$ Furthermore, the risk of aspiration from bleeding is an added challenge that makes it very difficult to secure the airway for surgery. In addition, hemodynamic instability and hypoxia as a result of bleeding and inability to secure the airway can be further compromised with a prolonged or failed intubation. ${ }^{47}$ Postoperative hemorrhage is the most serious complication of tonsillectomy. The common time for postoperative bleeding varies from the first 6 hours to 7 to 8 days postoperatively. ${ }^{48}$ However, bleeding has been reported up to 6 months after tonsillectomy. Most of the bleeding originates from the tonsillar fossa and often requires surgical exploration and hemostasis. Bleeding is usually sudden and occurs most often when the "scab" falls off the tonsil area 7 to 10 days after the surgery. These patients are considered as having a full stomach because constant bleeding results in patients swallowing large amounts of blood. Severe blood loss and a compromised airway are the 2 main reasons for morbidity and mortality of these patients. ${ }^{49}$ 


\section{Aspiration of foreign bodies}

Aspiration of foreign bodies by children is a common problem around the world. Asphyxiation from inhaled foreign bodies is a leading cause of accidental death among children younger than 4 years. The preoperative assessment should determine where the aspirated foreign body has lodged, what was aspirated, and when the aspiration occurred. If the foreign body is located in the trachea, the child is at risk for complete airway obstruction and should be taken urgently to the operating room. Conversely, the risk of complete airway obstruction is less if the object is firmly lodged beyond the carina. It is important to determine the type of foreign body: Organic materials can absorb fluid and swell, oils from nuts cause localized inflammation, and sharp objects can pierce the airway. The time since the aspiration should be established because airway edema, granulation tissue, and infection may make retrieval more difficult with delayed presentations. ${ }^{50}$ Major iatrogenic complications were specified in 21 studies with 9437 children with aspirated foreign bodies. These complications included laryngeal edema or bronchospasm, pneumothorax, pneumomediastinum, cardiac arrest, tracheal or bronchial laceration, and hypoxic brain damage. These major complications occurred in 91 of these 9437 children $(0.96 \%)$. Of the 11 cardiac arrests that were reported, 1 occurred after induction of anesthesia in a child who was hypoxic on admission, 5 occurred during bronchoscopy because of hypoxia (3) or bleeding (2), and the remaining 5 were not specified. Twenty-five deaths occurred in the 5 largest series with 5927 children $(0.42 \%){ }^{51-55}$ In a study conducted by Marinov et al. the incidence of major complications were $30.83 \%$ for tracheal or bronchial laceration, $15.83 \%$ for the bronchospasm and $7.5 \%$ for the laryngospasm. The reason of this high incidence of major complications is that most of the foreign bodies stayed in airways more than 10 days. $^{56}$

\section{References}

1. Marinov Ts., M. Belitova, T. Popov, N. Nizamova, J. Rangachev, D. Popova. Anesthetic Challenges During Laser Surgery of the Larynx Part 1. Biological Effect And Specific Laser Hazards. Otorhinolaryngology International Bulletin, XV, 2019;3:10-13.

2. Antila HM, Illman HS, Hurme S, Grénman R: Tubeless anaesthesia with sevoflurane and propofol in adult laryngeal surgery, Eur Arch Otorhinolaryngol 268:93-99, 2011.

3. Leonard PF: The lower limits of flammability of halothane, enflu $\neg$ rane, and isoflurane, Anesth Analg 54:238, 1975.

4. Hunton J, Oswal VH: Anaesthetic management for carbon dioxide laser surgery in tracheobronchial lesions, Anaesthesia 42:1222, 1987.

5. Cozine K, Rosenbaum LM, Askanazi J, et al: Laser-induced endo $\neg$ tracheal tube fire, Anesthesiology 55:583, 1981.

6. Sosis MB: Airway fire during CO2 laser surgery using a Xomed laser endotracheal tube, Anesthesiology 72:747, 1990.

7. American Society of Anesthesiologists Task Force on Operat $\neg$ ing Room Fires: Practice Advisory for the Prevention and Man $\neg$ agement of Operating Room Fires: an Updated Report by the American Society of Anesthesiologists Task Force on Operating Room Fires, Anesthesiology $118(2): 271-290,2013$

8. Sosis MB, Dillon FZ: Saline-filled cuffs help pevent laser-induced polyvinyl chloride endotracheal tube fires, Anesth Analg 72: 187-189, 1991.

9. Marinov Ts., M. Belitova, T. Popov, N. Nizamova, J. Rangachev, D. Popova. Anesthetic Challenges During Laser Surgery of the Larynx Part 2. Operating Room Fire. Otorhinolaryngology International Bulletin, XV, 2019;3:14-19.

10. Marinov Ts., M. Belitova, T. Popov, D. Konov, M. Tsekova-Chernopolska, M. Milkov. Incidence and significance of laryngeal carcinoma. Oto Rhino Laringology International Bulletin, XIV, 2018;1:23-27.

11. Popov, T. M., Dikov, T., Goranova, T. E., Stancheva, G., Kaneva, R. P., Todorov, S., Stoyanov, O., Rangacev, J., Marinov, T., Popova, D. P., Mitev, V. I., KONOV, D. (2015). Macrophageal infiltration and microvessel density in laryngeal carcinoma: study of 52 cases. Acta Otorhinolaryngologica Italica, 35(5), 321-324.

12. Timon CI, Gullane PJ, Brown D, Van Nostrand AW. Hyoid bone involvement by squamous cell carcinoma: clinical and pathological features. The Laryngoscope 1992; 102:515-520.

13. Marinov Ts., M. Belitova, T. Popov, J. Rangachev, O. Stoyanov, D. Popova. Dysphagia in Patients after Total Laryngectomy Oto Rhino Laringology International Bulletin, XV, 2019;2:9-12.

14. Popov T., D. Konov, M. Tsekova-Chernopolska, Ts. Marinov, M. Belitova, M. Milkov. Surgical treatment of laryngeal carcinoma. Oto Rhino Laringology International Bulletin, XIV, 2018;1:12-17.

15. Marinov Ts., M. Belitova, T. Popov. Ventilatory and haemodynamic pattern in patients undergoing laryngeal fronto-lateral resection. Anaesthesiology and Intensive Care, XLVII, 2018;3:6-9.

16. Marinov Ts., M. Belitova, T. Popov, J. Rangachev, D. Popova. Hemodynamic responses to different methods for upper airway instrumentation in patients undergoing laryngectomies. Oto Rhino Laringology International Bulletin, XIV, 2018;3:19-27.

17. Marinov Ts., M. Belitova, T. Popov, J. Rangachev, O. Stoyanov, D. Popova. Upper airway instrumentation in patients with laryngeal obstruction. Oto Rhino Laringology International Bulletin, XV, 2019;2:27-32

18. Marinov Ts., M. Belitova, T. Popov. Anesthetic problems in patients with laryngeal carcinoma. Anaesthesiology and Intensive Care, XLVII, 2018;3:19-21

19. Marinov Ts., M. Belitova, T. Popov. Algorithm for establishing upper airway patency in patients with laryngeal obstruction. Anaesthesiology and Intensive Care, XLVIII, 2019;1:7-9.

20. Marinov Ts., M. Belitova, T. Popov, J. Rangachev, O. Stoyanov, D. Popova. Use of laryngeal mask airway in patients with carcinoma of the larynx. Oto Rhino Laringology International Bulletin, XV, 2019;2:21-26. 
21. Marinov Ts., M. Belitova, T. Popov, D. Konov, M. Tsekova-Chernopolska. Laryngeal mask or endotracheal intubation in patients with laryngeal carcinoma. Oto Rhino Laringology International Bulletin, XIV, 2018;1:5-11.

22. Marinov Ts., M. Belitova, T. Popov. Laryngeal mask - new challenges. Anaesthesiology and Intensive Care, XLIV, 2015;4:26-29.

23. Marinov Ts., M. Belitova, T. Popov, D. Konov, M. Tsekova-Chernopolska. Determination of respiratory obstruction in patients with carcinoma of the larynx. Oto Rhino Laringology International Bulletin, XIV, 2018;1:18-22.

24. Marinov Ts., M. Belitova, T. Popov, J. Rangachev, D. Popova. Difficult intubation in patients with carcinoma of the larynx and hypopharynx. Oto Rhino Laringology International Bulletin, XIV, 2018;3:10-13.

25. Rosenblatt W, Ianus AI, Sukhupragarn W, Fickenscher A, Sasaki C. Preoperative endoscopic airway examination (PEAE) provides superior airway information and may reduce the use of unnecessary awake intubation. Anesth Analg. 2011;112:602-607.

26. Popov, T. M., Marinov, T., Rangachev, J., Konov, D., \& Belitova, M. (2017). Cricotracheal Resection in a Patient with Severe Subglottic Stenosis-Advantages of a Temporary Non-Cannulated Tracheostomy. Balkan medical journal, 34(2), 165-167.

27. Konov D., T. Popov, M. Tsekova-Chernopolska, Ts. Marinov, M. Belitova, M. Milkov. Postoperative complications after laryngectomy. Oto Rhino Laringology International Bulletin, XIV, 2018;1:28-31.

28. Marinov Ts., M. Belitova, T. Popov. Somatic problems in patients undergoing laryngectomy. Anaesthesiology and Intensive Care, XLIV, 2015;4:30-33

29. Marinov Ts., M. Belitova, T. Popov. Characteristics of patients with laryngeal carcinoma in Bulgarian population. Anaesthesiology and Intensive Care, XLV, 2016;3:11-14.

30. Marinov Ts., M. Belitova, T. Popov, J. Rangachev, D. Popova. Postoperative cardiac complications in patients undergoing laryngectomies. Oto Rhino Laringology International Bulletin, XIV, 2018;3:28-33.

31. Marinov Ts., M. Belitova, T. Popov, J. Rangachev, D. Popova. Risk factors for periopertive complications in patients undergoing laryngectomies. Oto Rhino Laringology International Bulletin, XIV, 2018;3:14-18.

32. Tz. Marinov, T. M. Popov, M. Belitova. Laryngeal Mask Ventilation during Tracheostomy Improves Intraoperative Hemodynamic Stability in Patients Undergoing Total Laryngectomy. Acta Medica Bulgarica, Vol. XLVI, 2019;3:5-9.

33. Pollard BJ: Anaesthesia for laryngeal microsurgery. Anaesthesia 23:534-542, 1968.

34. Glass PS, Gan TJ, Howell S: A review of the pharmacokinetics and pharmacodynamics of remifentanil. Anesth Analg 89:S7-S14, 1999.

35. Nekhendzy V, Guta C, Champeau M: Otolaryngology-head and neck surgery. In Jaffe RA, Samuels SI, editors: Anesthesiologist's manual of surgical procedures, ed 4, Philadelphia, 2009, Lippincott Williams \& Wilkins, pp 174-258.

36. Zeitels SM, Burns JA, Dailey SH: Suspension laryngoscopy revisited. Ann Otol Rhinol Laryngol 113:16-22, 2004.

37. Crockett DM, Scamman FL, McCabe BF, et al: Venturi jet ventilation for microlaryngoscopy: Technique, complications, pitfalls. Laryngoscope 97:1326-1330, 1987

38. Kanagalingam J, Hurley R, Grant HR, Patel A: A new technique for the management of inaccessible anterior glottic lesions. J Laryngol Otol 117:302-306, 2003.

39. Chang CH, Bai SJ, Kim MK, Nam SB: The usefulness of the laryngeal mask airway Fastrach for laryngeal surgery. Eur J Anaesthesiol 27:20-23, 2010.

40. Mandel JE: Laryngeal mask airways in ear, nose, and throat procedures. Anesthesiol Clin 28:469-483, 2010.

41. Ferson DZ, Rosenblatt WH, Johansen MJ, et al: Use of the intubating LMA-Fastrach in 254 patients with difficult-to-manage airways. Anesthesiology 95:1175-1181, 2001.

42. Kihara S, Watanabe $\mathrm{S}$, Taguchi N, et al: A comparison of blind and lightwandguided tracheal intubation through the intubating laryngeal mask airway. Anaesthesia 55:427-431, 2000.

43. Joo HS, Kapoor S, Rose FK, et al: The intubating laryngeal mask airway after induction of general anesthesia versus awake fiberoptic intubation in patients with difficult airways. Anesth Analg 92:1342-1346, 2001

44. Dimitriou V, Voyagis GS, Brimacombe JR: Flexible lightwand-guided tracheal intubation with the intubating laryngeal mask Fastrach in adults after unpredicted failed laryngoscope-guided tracheal intubation. Anesthesiology 96:296-299, 2002.

45. Van Zundert AA, Hermans B, Kuczkowski KM: Successful use of a videolaryngoscope in a patient with carcinoma of the oro $\neg$ pharynx and obstructed airway. Minerva Anestesiol 75:475-476, 2009.

46. Practice guidelines for management of the difficult airway: an updated report by the American Society of Anesthesiologists Task Force on Management of the Difficult Airway. Anesthesiology. 2003; 98(5):1269-1277.

47. Donlon JV. Anesthesia for eye, ear, nose, and throat surgery. In: Miller RD, ed. Anesthesia. Philadelphia, PA: Churchill Livingstone; 2000: 2173-2198

48. Ferrari LR, Gotta AW. Anesthesia for otolaryngologic surgery. In: Barash PG, Cullen BF, Stoelting RK, eds. Clinical Anesthesia. Philadelphia, PA: Lippincott Williams \& Wilkins; 2006:997-1012.

49. Cohen D, Dor M. Morbidity and mortality of post-tonsillectomy bleeding: analysis of cases. J Laryngol Otol. 2008;122(1):88-92.

50. Marinov Ts., M. Belitova, T. Popov, J. Rangachev, O. Stoyanov, D. Popova. Anesthetic Techniques and Complications for Airway Foreign Body Removal in Children. Otorhinolaryngology International Bulletin, XV, 2019;2:5-8.

51. Aydogan LB, Tuncer U, Soylu L, Kiroglu M, Ozsahinoglu C. Rigid bronchoscopy for the suspicion of foreign body in the airway. Int J Pediatr Otorhinolaryngol 2006;70:823-8

52. Tang LF, Xu YC, Wang YS, Wang CF, Zhu GH, Bao XE, Lu MP, Chen LX, Chen ZM. Airway foreign body removal by flexible bronchoscopy: experience with 1027 children during 2000-2008. World J Pediatr 2009;5:191-5

53. Eren S, Balci AE, Dikici B, Doblan M, Eren MN. Foreign body aspiration in children: experience of 1160 cases. Ann Trop Paediatr 2003;23:31-7

54. Hasdiraz L, Oguzkaya F, Bilgin M, Bicer C. Complications of bronchoscopy for foreign body removal: experience in 1,035 cases. Ann Saudi Med 2006;26:283-7

55. Hui H, Na L, Zhijun CJ, Fugao ZG, Yan S, Niankai ZK, Jingjing CJ. Therapeutic experience from 1428 patients with pediatric tracheobronchial foreign body. J Pediatr Surg 2008;43:718-21

56. Marinov Ts., M. Belitova, T. Popov. Most common complications after bronchoscopic airway foreign body removal in children. Aнестезиология и интензивно лечение, XLVIII, 2019;4:24-26. 